\title{
Lichen planopilaris
}

INSERM

\section{Source}

INSERM. (1999). Orphanet: an online rare disease and orphan drug data base. Lichen planopilaris. ORPHA:525

Lichen planopilaris (LPP) is a rare cutaneous variant of lichen planus (see this term) which affects hair follicles. It may occur on its own or in association with more common forms of lichen planus, usually classical type and/or oral lichen planus. 